\title{
PERCEPTION, CONNOTATION, TRANSLATION OF NUMBERS
}

\author{
Livio Clemente Piccinini \\ Mario Taverna \\ Ting Fa Margherita Chang \\ Giovanni Tubaro \\ Department of Civil Engineering and Architecture \\ Udine University, Italy
}

\begin{abstract}
The purpose of the note is to discuss the translation of the numbers from one language to another in order to retain their meaning (in this case it is easy) and to preserve their connotations (and this is the hard part, as in every translation). The lexical system of numbers is an excellent laboratory to study the semiotic phenomena of hypocoding and hypercoding at an intermediate level of complexity, that does not avoid the problems but still allows rigorous solutions. This problem takes a well-defined role in the two sections dedicated to perception and connotations, when some numbers assume the role of hypernyms similar to adjectives ,, some, many, too many”. The various languages do not use the same system of hypernyms, so the translation, beyond the literal meaning, requires a particular knowledge, typical of bilingualism.
\end{abstract}

Keywords: connotation, hypercoding, hypocoding, numer systems, semiosis, translation.

\section{Introduction}

A main problem of semiotics is the homomorphism between real world and its (conventional) representation. Mathematics has the advantage of a consolidated structure of „reality” that can be compared with long established language conventions. The paper shows that even at this level there exist some inconsistencies. As the surrounding world becomes more complicated and meaningful mathematics must renounce to some axioms, broadening its boundaries through probability and fuzziness. Corresponding mathematical vocabulary is no longer unambiguous, and changes from one language to another, generating problems of translation.

In the sciences, including social sciences as taught by Martinet (1985) in the first two chapters, it is essential to define precise areas of relevance. However, there is the risk of paying the accuracy and logic correctness with reductionism, which prevents to analyze phenomena lying at the margins between various disciplines. Complexity theory accepts fuzzy positions that allow achieving a holistic view. This is a critical point, since a Bayesian system of subjective probabilities becomes necessary and they may not coincide when different specializations converge in the same field. 
Semiotics is not exempt from these risks, because the context in which it operates is too rich, and a purely abstract frame would be excessively reductionist. It is therefore important to find realistic areas of experimentation of affordable complexity. The numbers can be a fruitful ground to operate at an intermediate level of complexity, which does not avoid the problems but still allows rigorous solutions. Compared to other systems (colors, sounds, natural elements) numbers have the advantage of order, separation, possibility of generating formal operations at various levels of abstraction and precision. Of course boundaries to the semiotic analysis of the numbers must be imposed, eliminating the cases in which they operate as labels (telephone, automobile, current account) and waiving the magic superstructures they gained in time.

\section{Numbers and structure}

The number is the lexical item easier to translate. In all modern languages its meaning finds the exact match. It has universal symbols (also in nonalphabetic languages such as Chinese) operating as ideograms. In addition, the components are mostly one-to-one with the linguistic structure: for example, in the number 391, we can identify five lexical items $<$ three-hundred-nine-ty-one $>$ that match exactly ideogram 391 as the three root ideograms $<$ three, nine, one $>$ correspond to the figures, while the third position (from the right) in the ideogram points $<$ hundred $>$ and the second $<$-ty $>$. The mechanism is to be compared with Chinese alphabetization as described by the authors (Piccinini et al., 2013, p. 441).

This smart notation, with its double match, reached the formal completeness with the invention of the symbol zero, which is relatively recent. Linguistically the settlement is older, but not so old that non-positional states fully vanished (compare the first two chapters of Boyer, 1968). The most stable heritage from the past is the sexagesimal/duodecimal system of Babylonian origin $<$ day, hour, minute, second $>$, but also mixed medieval systems such $<$ yard, foot, inch $>$, < pound, shilling, penny $>$ survived. In some cases there are traces of the base 20, typical of the Germanic languages, where the ancient $<$ skor> meant notch, tally, twenty. Score survives in English and traces of the system are also found in French for the numbers between 70 and 100 (but not in other francophone countries).

The regular numbering system goes into crisis when the numbers become very large. Already thousand derives from an original Old Nordic <thusund $>$ (Eco, 2003) which meant numberless. Million is a derivative of the Latin $<$ mille/milia $>(=1000)$, but in this case no ambiguity arises. A big linguistic and practical problem is that in America Billion means 1,000 millions, while in England it means 1,000,000 millions, that is 1 trillion. In many systems the old terminal number was myriad (myrioi, myriades) that sometimes assumed the 
precise meaning of 10,000 , sometimes retained the generic value of ,great many" as pointed out (Rocci, 1953, p. 1260).

In Chinese (Zhang, 2006, p. 64 and Zhao \& Gatti, 1996, p. 57 and 350), 10,000 is the basis of the construction of large numbers since 1 万 (yi wàn) means 10,000 and 1 亿(yi yì) means 10,000 times 10,000, i.e. 100 million. In China there are no terms corresponding to a million and a billion, which become therefore 百万(băi wàn $=100$ times 10,000) and 十亿 (shí yì $=10$ times $100,000,000)$ respectively. For millionaire there is the regular construction 百万富翁 (băi wàn fù wēng $=100$ times 10,000 rich father). Note that to say billionaire, next to the regular <Billion Man>, there is also the hyperbolic expression 亿万富翁 (yì wàn fù wēng $=, 100$ million - 10 thousand - rich father" $)^{5}$.

It is interesting that in Chinese 万 (wàn) still retains also the meaning of $<$ great number $>$, so that the translation of the famous $<$ Pantheon $>$ Temple in Rome (its name in Greek means Temple of $<$ All the Gods $>$ ), becomes $<$ Temple of the 10,000 Gods $>$, and 10,000 perceptually seems a quantity larger than all.

The linguist can observe the small gaps that creep into the perfection of decimal numbering system. Apart from the folklore of the French, in many languages there is a power of attraction of the round figures towards adjacent numbers: in Latin there were undeviginti, duodeviginti $(19,18)$ - but there are also the Germanic numbers elf/eleven, zwoelf/twelve, that meant one more and two more (Fowler \& Fowler, 1964). The subtractive model still holds for the clock: in English twenty minutes to four is standard, while three-forty is used only in the time-tables. In Italian the backward model mostly operates up to fifteen minutes, so that $<$ tre e quaranta $>$ would be standard and $<$ venti alle quattro $>$ sounds cumbersome.

\section{The perception of the number}

It is more interesting to observe the number before it enters the domain of mathematics. The number is felt as a part of the language rather than of mathematics and so is a real signifier. But what is its meaning? Up to four, five subitizing (instant perceptual glance) allows to recognize small numbers of objects without counting. Stafford in section 35 reproduces simple experiments that show the possibility of exact results in this range (Stafford \& Webb, 2005). If the number is higher a rough geometry allows simplifications of the count, since the set is decomposed into subsets immediately perceived and then the sum is performed.

Some numbers are associated with concepts or sensations: 12 is associated with the analogical clock or with a box almost square, the squares of digits are

\footnotetext{
${ }^{5}$ Remark that the same phenomenon holds in modern Greek, where million is $<$ ena ecatommyrio $>(=$ one 100 times 10,000$)$, even if <myrio $>$ alone in the spoken language is mostly replaced by $<$ deka chiliades $>$ (10 thousand).
} 
displayed as boxes filled with small squares, but already 100, and even more 1000 are associated with undefined feelings of crowding.

It is possible that subitizing represents the origin of grammatical designations of quantity. The Indo-European had the distinction between singular, dual, plural: the dual generally went out of use in historical times and now survives in Slovenian and in some Greek and Lithuanians dialects. The Russian has archaisms in declination which suggest the reference to terns and quadruples of objects. On the other hand there are languages like Chinese who do not have a mandatory distinction between singular and plural.

Almost all languages have the ability to designate fuzzy numerical aggregates at various resolution levels. Beyond subjective expressions such as "many, few" in all languages numberless is used to indicate an amount that escapes the count. There are expressions that combine a numeric value with uncertainty. Often they were related to the physical process of a reference mark with a notch, as in the case of score. In Chinese dozen can be translated as $<$ yi dà $>$, which literally means < $<$ one shot $>$. In many languages, there is a possibility to render a number fuzzy adding an adverb or an adjective (some in English, etwas in German, circa in Italian, 几(ji) in Chinese) but French developed the specific suffix $<$ aine $>$ that fathered $10 \rightarrow<$ dizaine $>(=$ half-a-score $)$, $12 \rightarrow<$ douzaine $>, 20 \rightarrow<$ vingtaine $>, 100 \rightarrow<$ centaine $>$. The luckiest was $<$ douzaine $>(=$ dozen $)$, that spread in almost all European languages; in Italian the complete set entered with the exception of $<$ hundred $>$ that continues uninterruptedly the Latin $<$ Centenarium $>$ as $<$ Centinaio $>$. Remark that in German $<$ Dutzend $>$ can also replace <etwas zehn>, unlike what happens in English where dozen is different from half-a-score. The diffusion path of new structures is to be compared with what happens in trade contacts as shown by Droli (Droli et al., 2014) where some form of hypocoding allows penetration outside the core business (= the pure language).

In the perception of numbers (as in the case of colors) you enter easily into hypocoding ${ }^{6}$, i.e. the phenomenon of semantic under-determination, due to linguistic or even perceptive inability. Often it is originated by a formal hierarchical system which provides a hypernym, that in some cases is welldefined, but in other cases segments the reality in an arbitrary manner, as is the case for the colors. As long as the morphology is different there is no possibility of confusing an exact number with a hypocoding, but often the very number (usually in round figures) acts as a hypernym. No sensible person thinks the Garibaldi's Thousand were exactly 1000, as no one thinks that the 100,000 at Wembley stadium were 100,000, but when we say the number 1343 the meaning cannot be other than 1343 (apart the computational possibility of fractions). For the dates usually there is no ambiguity, since for practical reasons we point out when the use is fuzzy. In a history text even 1000 usually means 1000 . In

\footnotetext{
${ }^{6}$ As a reference a fundamental text is due to Eco (1975) in particular section 2.14.4 for hypocoding and 2.14.3 for hypercoding, that will be used in the next section.
} 
computing, on the contrary, $\mathrm{K}$ (which should mean 1000) stays for 1024 , as $\mathrm{M}$ (mega, which should mean 1,000.000) means instead 1,048,576. A number that ends with a non-zero digit is not considered a hypernym but when it ends with a sequence of zeros, it is usually interpreted as a hypernym. Should the statement: „In this room there are 500 people" be interpreted as an exact number, a lexical additional clarification is needed: „In this room there are exactly (or just) 500 people". In the statistical tables sometimes the context is clear since in the same column round numbers and non-round numbers are aligned. Sometimes the expedient is to add one or more decimal places, so that the exact figure 100 is written as 100.00 .

The hypernyms of numbers do not allow exact calculations, but sometimes allow fuzzy calculations, under two conditions, that are not used as a synonym of a very large or a terminal number and that they are of the same order of magnitude. Remark the indifferent use of million or billion with reference to a large amount, with a difference by factor thousand. There are many millionaires, but billionaires are much less! These numbers do not allow exact arithmetic operations. A billionaire who takes off a million remains a billionaire, but if the operation is repeated a thousand times he would no longer have anything! Recall also the joke of the shepherd who had three sheep and was close to a large flock. When asked how many sheep were on the meadow he answered 1003, as over one thousand sheep of the flock there were his three sheep.

\section{Number and connotation}

What tells us a number? Certainly is part of a sequence (or a nursery rhyme), and is placed at some point of this sequence. But what are the mental associations that it generates, i.e. which hypercoding is tagged with? We usually say that a number is large or small, what does not make sense unless there is a context that gives some fuzzy information. The experiments conducted by the authors show that in front of the request „Write down a big number” (without any context!) very few interlocutors refuse to carry out. There are various types of execution. Generally they write a sequence of 6 to 8 digits where the figures may be either random, or all equal to 9 , or all equal to 1 ; a slight variant is a sequence of zeros preceded by a single significant digit. School reminiscence sometimes leads to exponential notation. A fairly low percentage $(20 \%)$ write controversially a single digit number in very large format. It is clear that the test would give a very different outcome if it were conducted orally, since then a number such as $1,000,000$ is not equivalent as fatigue of execution to a number such as 999,999 . On the other hand the oral test should be conducted by 
isolating the participants otherwise there would almost certainly the effect of an auction $^{7}$.

The emphasis can be achieved by repeating large numbers. In Catullus (1958) we find the passage

$$
\begin{aligned}
& \text { Da mihi basia mille, deinde centum } \\
& \text { Dein mille altera, dein secunda centum, } \\
& \text { deinde usque altera mille, deinde centum } \\
& \text { Dein, cum milia multa fecerimus, } \\
& \text { conturbabimus illa, ne sciamus }{ }^{8} \text {. }
\end{aligned}
$$

Apart round figures, Catullus was very found of 300, a hyperbolic number with a realistic tinge. Some examples are 9,2;11,18; 12,10;29,14; 48,3.

The connotations of the number, as for many attributes, arise from its basic ambiguity. Its meaning is very abstract but on the other hand we have the experience of the numbers in various contexts, where the number glues its abstraction with concrete meanings, generating a hypercoding. „A thousand spectators" reminds a full theater (or an empty stadium), „five feet high” makes us think of a person of short stature. It seems that at the origins of homo sapiens numbers were perceived only in relation to the objects that they specified. The acquisition of the number as a means to segment the reality is more recent and belongs to the historical period. Even today the conversion from the American sequence $6,8,10,12,14$ into extra-small, small, medium, large, extra-large shows us that numbers often serve to segment the reality instead of counting or measuring. Sometimes the numbers retain the significance of magnitude and allow both to segment the reality and to carry out the calculations on it. The transition is not always easy, since it requires a dribbling between right brain and left brain applied to the same reality. The cognitive leap belongs to the experience of the child who in its ontogeny follows the human phylogeny, with the discontinuities mentioned by Freudenthal in particular in 2.2 (Freudenthal, 1991) with reference to his experience remembered (Freudenthal, 1980).

At a time when the number becomes a tool for segmenting the reality possible problems of translation may arise for the connotations that it is to assume. Sometimes the number is used to give a feeling of precision, perhaps in an ironic sense. In Dante's Divine Comedy (Alighieri, 2001) devil Malacoda with notary pique recalls

In just five hours it will be, since the bridge fell, A thousand two hundred sixty-six years and a day; That was the time the big quake shook to Hell Inf $21,112-114$

\footnotetext{
${ }^{7}$ The main property of natural numbers is the existence of a successor. We have seen that on the practical experience there exists an empirical fuzzy bound that is not surmountable. Even a computer is a finite machine with finite operating limits.

${ }^{8}$ Give me thousand kisses, then hundred/ then thousand more, and hundred again/ thousand more, hundred again/then, when we make many thousands/we shall mix them, so that we cannot know.
} 
In this case the accounts are accurate. Where you just cannot make ends meet, even using the lunar months, is in the genealogy of the patriarchs (Genesis 5 , especially in verse 27 where we find the 969 years of Methuselah).

\section{Numbers and translation}

Here is the simplest example: how to translate <thirty miles $>$ from English into Italian (or any other language where miles are not used)? The most obvious proposal is $<$ trenta miglia $=$ thirty miles $>$. However, despite being exact, it uses a term foreign to the Italian system of measurement so that it gives a foreign, perhaps exotic, connotation ${ }^{9}$ which was absent in the original text. At this point, it can be proposed to change the reference system: miles can easily ${ }^{10}$ be converted in $\mathrm{km}$, but in this case the number must be updated. The most sensible translation is fifty kilometers although it is incorrect in that it should be $48 \mathrm{~km}$. This last translation (almost) exact presents a number with two significant figures in place of the original hypernym. In a technical manual it can be accepted, but in a translation attentive to the style that would create a distorted effect. Things are even more complicated in the translation of $30 \mathrm{mph}$, since 50 $\mathrm{km} / \mathrm{h}$ gives a good perception, familiar to all drivers, but not exact. For the record, the translation of $30 \mathrm{mph}$ into $48 \mathrm{~km} / \mathrm{h}$ historically existed in the early fifties in the Free Territory of Trieste, then under British government, and represented the speed limit along the coastal road.

The mechanical measurements are often expressed in inches and fractions such as 1/2, 1/4, 3/8 also in non Anglo-Saxon countries, with effect of embarrassment for the layman that perceives them as if they were ideograms.

Positivism joined with the transition to the metric system could result in hilarious effects. The „metric" tour guides were concerned to determine the length of the monuments in feet and inches, and then translate them into meters and centimeters. The strangest effects, however, are found in the less educated works. In (AA.VV., 1891) a Ferrara pound, of 12 ounces, is translated as fussiness in $\mathrm{Kg}$. It reads just in the first pages

Cut Kg. 0.086 of bacon into slices thin as a scudo, cover the bottom of a large saucepan, and above this cut an onion a little thicker, then Kg. 1.380 beef without bones, fresh and lean, cut in two-finger-thick slices; ...

The amenity arises not only from the absurdity of the prescribed quantities (which scales are used?) but also from the contrast between coarse and empirical measures (scudo, a coin; two fingers) with high precision measurements. Note

\footnotetext{
${ }^{9}$ Compare Eco (2003) in ch. 3 of where Reversibility and Effect are studied.

${ }^{10}$ We recall that even to-day many different types of mile are still in use. They range from the statute mile (this one), 1609.344 meter long to the geographic mile, 1855.4 meter long. Till the end of nineteenth century there were many other, in particular German miles were completely different and ranged from 6910 meters (Bohemian) to 8888 meters (Badish).
} 
also the use of the kilogram instead of a gram or other units. The comic effect arises from the clash of two different systems that compete on the same grounds, following the model of Ruskin discussed by Kincans (2013, p. 378). ${ }^{11}$

For the nineteenth-century positivism it was a huge blow to discover that in the census the exact age classes could be missed. In the acts of the first census of the Kingdom of Italy, which was held (nominally) at midnight of December 31, 1861 , we find accumulations of inhabitants in the round classes of $20,30,40 \ldots$, a slight peak at $25,35,45, \ldots$ and intermediate ages almost empty, since the exact data were known primarily by nobles and bourgeois. The first census was still in the realm of hypernyms.

The choice of hypernyms in the metric system was originally established ten in ten (today it goes thousand in thousand), but this excessive availability caused some customary selections with differences between different countries. In Italy millimeters, centimeters, meters, kilometers dominate although at the beginning of the twentieth century there were abortive attempts to introduce the myriameter; hectometer survived only as hectar, 10000 square meters. In Austria a singular textbook (Rusch, 1903) used the square myriameter, though using square $\mathrm{km}$ for the density of the inhabitants. The decameter was not defended by anyone and the decimeter led a wretched existence limited to the school. For weights gram, and kilo[gram] were popular, but the intermediate sections oscillated between hecto[gram], deka[gram], quarter, half quarter. The German half quarter $(=125 \mathrm{~g})$ was reintroduced recently by Community rules. The country economically dominant forces his tongue!

In the case of currency, translation becomes impossible even within the same unit of measure because of economic evolution and inflation. A further information on the pricing system of the time is unintentionally provided so that again there is hypercoding. Often works of little literary value, thanks to this low profile, become over time sources of striking documentation.

\section{Conclusions}

Bilingualism related to the numbers is not the simple ability to count in different languages, which is one of the easiest to acquire. It relies on the perception of the connotations associated with different measurement systems. A continental knows that a mountain 4000 meters high belongs to the highest peaks of the Alps. But does he know with equal certainty that a mountain of 13,000 feet does not belong to Himalayas? Can we perceive that at 100 Fahrenheit the weather is hot, but not yet so hot as in the heart of the Sahara? And does an American perceive that 39 degrees represent a high fever? There are people who work with two systems of measurement, but in different

\footnotetext{
${ }^{11}$ Slightly different is the classical case of pleasure $($ Dulce $=$ sweet $)$ considered by Lucretius $(1900)$ in 2, 1-6, where the essential asymmetry of converging alternatives leads to opposition (and relief) rather than comic effects.
} 
contexts: a continental airplane pilot measures land distances in kilometers and the heights of the mountains in meters, but measures the distances to travel by plane in miles and flight altitudes in feet. It is not automatic that he also has the perception that 100 feet are 30 meters, because this measure may be out of his range for English measure system. This phenomenon recalls the entry barriers that exist in economics, and can be compared with the discussion (Chang et al., 2015).

A daily case of bilingualism occurs in the perception of speed: the speed is the distance traveled in a given time but can also be perceived as the time required to travel a given distance (that is its inverse). For motor vehicles the speed can be read on the speedometer, while walking you see on the clock the time taken. The conversion is not intuitive and can mislead even engineering students.

Investigations should be carried out on the psychology of bilingualism in particular in cases of emigration. It seems that there are systems anchored to the first learning so that a conversion becomes slow and uncertain. This fact is confirmed by the difficulty that people used to perceive the prices in national currencies find with euro account, even after more than ten years; it is observed that when there is the need to have a quick perception of the amounts, they are still forced to bring the amount to the old currency. Beyond a certain age it is difficult to create new mechanisms of complete perception, even if you can detect the presence of bands of „bilingualism” in particular areas of frequent use.

\section{Summary}

The note shows that beyond the mechanical translation of a number from one language to another, there are many problems related to the field of the significance of the number. This paper only considers the natural numbers, which are learned before schooling, so that the phenomena of perception both exact and approximate are free from the influence of superimposed technicalities. This substrate has profound moments of hypocoding and approximation which are alternated with moments of hypercoding where the number assumes an emphatic fashion. Sometimes the reversal of its dimensional scale is reached, as when the phrases „I told you a hundred times,” and „I told you a thousand times ,are considered equivalent or a person is defined as ,a millionaire" instead of ,a billionaire”, with the same meaning. The hypercoding can even cancel the original meaning of the number substituting a new dominant connotation. At the end, the note focuses on perceptive bilingualism of numbers, which could be investigated and compared in the euro-area countries where there was instant switching from a monetary system to another in the (theoretical) absence of inflation. In particular it would be worth to compare the speed of adaptation of three classes: older generations, non reactive; intermediate generations, with stable number perception with ability to react; younger generations that experience an evolving system just begun. 


\section{SOCIETY. INTEGRATION. EDUCATION. Volume III}

\section{References}

Alighieri, Dante (2001). Divina Commedia. Engl. Transl. by John Ciardi. New York: Signet Classics.

AA.VV. (1891). Cucina pratica ferrarese. Milano: Bietti Ed.

Boyer, C.B. (1968). A history of Mathematics. John Wiley \& Sons.

Catullus, C. Valerius (1958). Carmina recognovit Mynors, R.A.B.. Oxford: Clarendon Press.

Chang, Ting Fa M.; \& Droli, Maurizio; \& Iseppi Luca (2015). The black box of economic interdependence in the process of structural change. The International Food and Agribusiness Management Review 2015/2, 18(1), 105-126.

Droli, Maurizio; Chang, Ting Fa M.; \& Iseppi, Luca; \& Piccinini, Livio C. (2014). Managing trade contacts in HotRest intermediate markets: a resource-based view analysis in EU countries. Tourism Economics, 20, 757-778.

Eco, Umberto (1975). A Theory of Semiotics, Indiana: University Press.

Eco, Umberto (2003). Dire quasi la stessa cosa Milano: Bompiani.

Fowler, H.W.; \& Fowler, F.G. (1964). Concise Oxford Dictionary Oxford: Clarendon Press

Freudenthal, Hans (1980). Lernprozesse Beobachter Neue Sammlung 20, 328-340

Freudenthal, Hans (1991). Revisiting Mathematical Education. China Lectures. Dordrecht: Kluver Academic Publishers

Kincans, Vladimir (2013). Humour and Laughter in Pedagogical Communications. Society, Integration, Education, Vol.2, 375-385

Lucretius, T. Carus (1900). De rerum natura recognovit Bayley, C.. Oxford: Clarendon Press. Martinet, André (1985). Syntaxe générale. Paris: Armand Colin Ed.

Piccinini, Livio C.; \& Chang, Ting Fa M.; \& Tubaro, Giovanni (2013). How to overcome analphabetism in reading Chinese characters. Society, Integration, Education, Vol.2, 438-448

Rocci, Lorenzo (1953). Vocabolario Greco-Italiano, Roma: Società.Editrice Dante Alighieri.

Rusch, Gustav (1903). Lehrbuch der Geographie,.Wien: Verlag Pichlers Witwe \& Sohn.

Stafford, Tom; \& Webb, Matt. (2005). Mind Hacks O'Reilly Media Inc.

Zhang, Shihua. (2006). Dizionario Conciso Italiano-Cinese e Cinese-Italiano. Shanghai: Shanghai Foreign Language Educational Press.

Zhao, Xiuying; \& Gatti, Franco; (1996). Dizionario Cinese. Bologna: Zanichelli. 